\title{
Effectiveness of exercise on fatigue in hemodialysis patients: a randomized controlled trial
}

\author{
Farzaneh Salehi ${ }^{1}$, Mahlagha Dehghan² ${ }^{2}$, Parvin Mangolian Shahrbabaki ${ }^{3^{*}}$ and Mohammad Reza Ebadzadeh ${ }^{4}$
}

\begin{abstract}
Background: Hemodialysis is one of the common therapies in patients with end-stage renal disease. Even patients who receive regular treatment suffer from fatigue, which is one of the main factors leading to poor quality of life. This study aimed to determine the effectiveness of exercising on mini-bikes on fatigue in hemodialysis patients.

Methods: This study is a randomized controlled clinical trial. Thirty-seven hemodialysis patients participated in the study. The patients were randomly allocated to either the intervention group $(n=20)$ or the control group $(n=17)$. The participants in the intervention group exercised on mini-bikes for 20 min twice a week for 3 months. The patients' fatigue was measured four times during and after the intervention. Multidimensional Fatigue Inventory was used to measure the fatigue level. The total score in the MFI is 4 to 20 for each domain, with the resulting total fatigue score ranging from 20 to 100; thus, the higher the score, the higher the level of fatigue. Data were analyzed by SPSS 18. The repeated measures ANOVA was used to compare the fatigue scores within each group and between the groups at different times.
\end{abstract}

Results: The mean score of fatigue in the intervention group at the beginning was $58.80 \pm 15.29$, which steadily decreased to $58.78 \pm 13.54,58.75 \pm 14.73,54.20 \pm 15.16$, and $54.23 \pm 13.60$ for the 3 months of intervention and 1 month post-intervention, respectively. In contrast, in the control group, this score was $62.53 \pm 16.32$ in the beginning, increasing to $64.03 \pm 13.91,64.22 \pm 13.07,69.53 \pm 9.22$, for the 3 months of intervention and $70.34 \pm 7.69$ one-month post-intervention. There were significant differences between the intervention group and the control group in the third month $(P=0.001)$ and 1 month after the intervention $(P<0.001)$.

Conclusions: The results showed that rehabilitation through exercising using mini-bikes had a significant impact on preventing further fatigue build-up in hemodialysis patients, making the mini-bike an effective nonpharmaceutical intervention preventing the increase in fatigue experienced by patients undergoing hemodialysis.

Trial registration: Iranian Registry of Clinical Trials: IRCT20180314039100N1. Registered 10 June 2018.

Keywords: Fatigue, Hemodialysis, Exercise, Cycling

\footnotetext{
*Correspondence: mangolian167@yahoo.com; p_mangolian@kmu.ac.ir

${ }^{3}$ Nursing Research Center, Razi Faculty of Nursing and Midwifery, Kerman University of Medical Sciences, Kerman, Iran

Full list of author information is available at the end of the article
}

(C) The Author(s). 2020 Open Access This article is licensed under a Creative Commons Attribution 4.0 International License, which permits use, sharing, adaptation, distribution and reproduction in any medium or format, as long as you give appropriate credit to the original author(s) and the source, provide a link to the Creative Commons licence, and indicate if changes were made. The images or other third party material in this article are included in the article's Creative Commons. licence, unless indicated otherwise in a credit line to the material. If material is not included in the article's Creative Commons licence and your intended use is not permitted by statutory regulation or exceeds the permitted use, you will need to obtain permission directly from the copyright holder. To view a copy of this licence, visit http://creativecommons.org/licenses/by/4.0/ The Creative Commons Public Domain Dedication waiver (http://creativecommons.org/publicdomain/zero/1.0/) applies to the data made available in this article, unless otherwise stated in a credit line to the data. 


\section{Background}

The annual 5-6\% growth in the number of chronic kidney-failure patients makes this disease one of the most important problems in every country, and hemodialysis is the most prominent method for treating patients suffering from it [1]. Hemodialysis patients are constantly dealing with numerous problems such as fatigue due to the chronic nature and the side effects of hemodialysis, which negatively affects the quality of their lives [2]. Fatigue is a subjective sense of weakness, loss of energy, tiredness, and malaise. It is known as a biological warning when human health is at risk. This disorder reduces the sense of wellbeing and has numerous effects on the physical, emotional, and cognitive dimensions of patient experience [3, 4].

Fatigue reduces self-care activities, disrupts familial and social roles, and decreases the ability to perform routine activities and can lead to unemployment and increased dependence on health care, negatively affecting patient quality of life and self-confidence [5, 6]. 60 to $97 \%$ of hemodialysis patients experience some level of fatigue compared to patients with normal kidney function [7]. Some factors leading to fatigue in hemodialysis patients include uremia, anemia, sleep disorders, and psychosocial distress, many of which may be amenable to intervention.

Despite the availability of pharmaceutical interventions such as L-carnitine, used for alleviating fatigue, side effects such as gastrointestinal disorders, nausea, vomiting, stomach upset, heartburn, diarrhea, and sleep disorders as well as drug interactions due to reduced renal excretion and increased drug toxicity have led to a greater tendency to use complementary therapies [8].

One of the important strategies for controlling some of these side effects is exercise [9]. Several studies have confirmed the positive effects of physical activities on different populations [10]. These effects include reduced cardiovascular disease, reduced mortality rates, improvement in and control of blood pressure, controlled blood glucose, increased sense of wellbeing, and improvement in physical performance $[9,11,12]$.

Arian and Mortazavi [13] demonstrated that 56\% of hemodialysis patients exercised less than once a week, $75 \%$ had severe limitations in doing heavy exercises, and $42 \%$ had average limitations in their daily activities. This could be due to anemia, blood circulation disorders in extremities, reduced heart performance, and decreased daily physical activity. Other important factors such as anxiety, depression, spending more time sleeping, and inactivity further limit the physical capacity of those undergoing dialysis [14]. Also, the lack of motivation and developing too many medical complications have been associated with a lower physical capacity in hemodialysis patients [15]. It seems that control of fatigue in hemodialysis patients can lead to physical betterment as well as psychological improvements such as reduction of depression and anxiety, improvement in self-care, reduction of dependence, and improvement in quality of life, the sense of wellbeing, and increased sleep quality in patients [16-20].

Muscle and joint stretching may be difficult for the elderly and those with bone problems. Also, the fistula in the forearm and being attached to a hemodialysis machine are serious barriers to performing stretching exercises, making it impossible to use this intervention during hemodialysis. Therefore, in order to overcome the limitations of the physical activity for patients under hemodialysis, we opted for the use of "mini-bikes", which are more affordable and accessible than other equipment and have far fewer ergonomic risks. A mini bike is much more suitable than a regular bike for exercise patients undergoing hemodialysis because it can easily be used for patients who have to remain in bed for as long as $3 \mathrm{~h}$. Minibikes can also benefit older patients and those with bone problems when used inactively. Such easily executable exercise can relieve the patient from the three- to four-hour inactivity during hemodialysis.

Due to the importance of fatigue, which is a neglected aspect of the treatment process of hemodialysis patients, and the emerging data showing that exercise is able to alleviate fatigue, this study aimed to assess the effect of exercising on mini-bikes on fatigue in hemodialysis patients, with the hypothesis that the use of mini-bikes could affect fatigue in patients undergoing hemodialysis.

\section{Methods}

\section{Study design and setting}

The present study was a randomized controlled clinical trial conducted in the hemodialysis units of Shafa Hospital and Jawad Al Aemeh Center, affiliated with Kerman University of Medical Sciences.

\section{Sample size and sampling}

As demonstrated in a previous study, where researchers examined the effect of an exercise program on reducing fatigue and improving sleep in long-term hemodialysis patients, the present study (16 interventions and 16 controls) had sufficient power $(80 \%)$ to detect a mean difference of fatigue score of 3.1 (Fatigue score: $\mu_{1}=7.6, \mu_{2}=$ 10.7, $\mathrm{S}_{1}=3.3$, and $\mathrm{S}_{2}=2.9$ ) [20].

The researcher selected eligible people after coordinating with the head of the hospital and the dialysis department. The inclusion and exclusion criteria are presented in Fig. 1. A total of 96 patients under hemodialysis were studied using the census method. Fifty-four patients were eligible to enter the study. The first researcher assigned twenty-seven patients to the intervention and control groups using the minimization method. First, the sex and age of the two groups were matched $( \pm 2)$, and they were then randomly allocated to one of the groups 


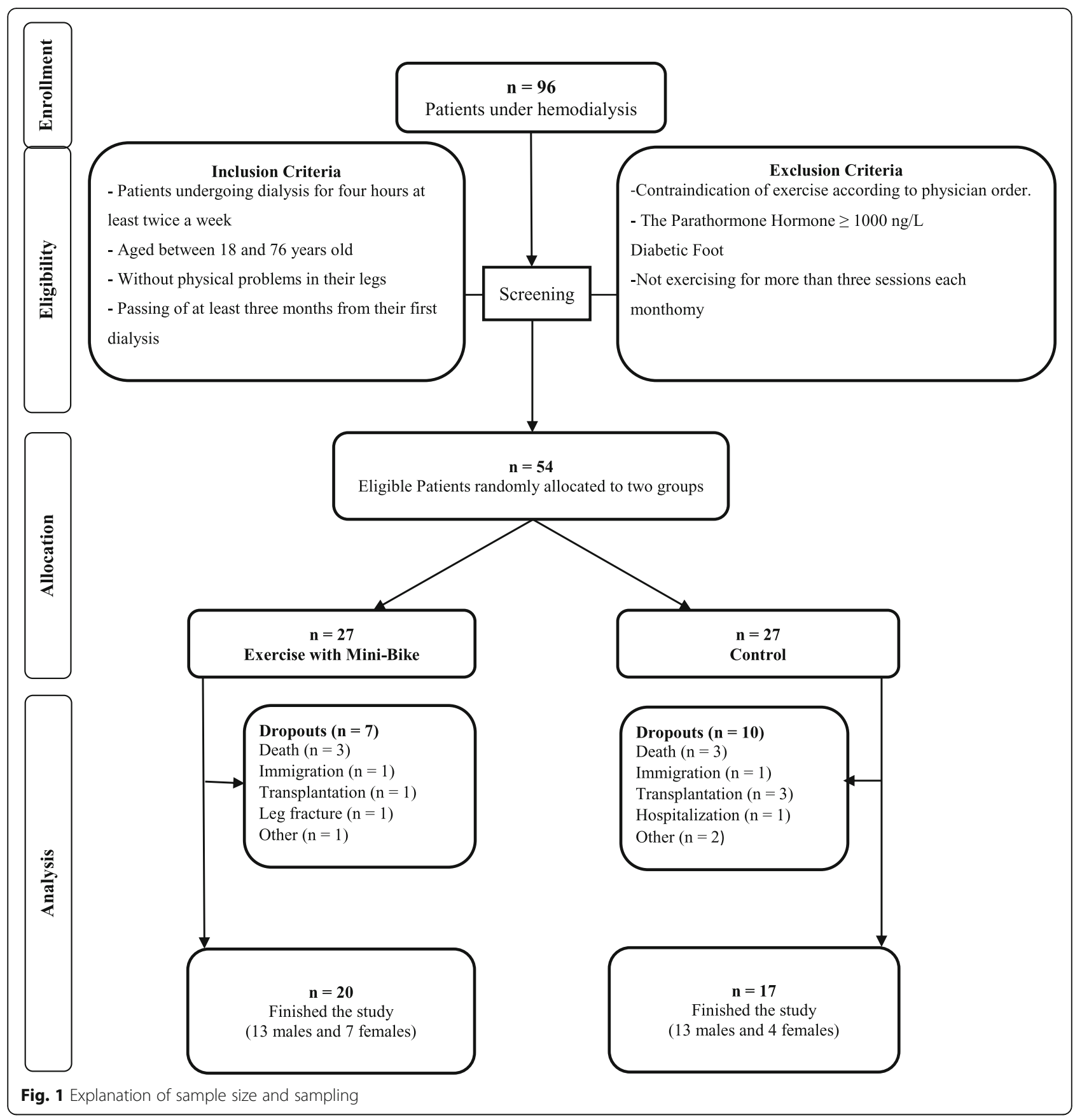

by throwing dice. Finally, 20 patients in the intervention group and 17 patients in the control group finished the study (Fig. 1).

\section{Measurement}

Demographic questionnaire and Multidimensional Fatigue Inventory (MFI) were used to collect information. The demographic questionnaire included questions on age, gender, education, income, the number of children, exercise, duration of dialysis, cause of dialysis, transplant rejection, and other diseases.
The MFI, used to measure the level of fatigue, included 20 items and 5 subscales of fatigue (4 questions), physical fatigue (4 questions), decline in activity (4 questions), decline in motivation (4 questions), and mental fatigue (4 questions). Scoring was done using a Likert 5-point scale $(1=$ Yes, entirely correct to $5=\mathrm{No}$, entirely wrong). The total score was 4-20 for each domain, leading to a total fatigue score ranging from 20 to 100 . The higher the score, the higher the level of fatigue [21]. The validity and reliability of the questionnaire have been confirmed in 
the Iranian population [22]. Many researchers have used this instrument to measure fatigue [23-25].

\section{Data collection and intervention}

After getting to know the patients undergoing hemodialysis the day before the study, a nephrologist examined the patients to make sure there was no medical restriction for entering the study. Afterwards, the MFI was completed by the intervention and control groups. Then, the exercise program was conducted twice a week for 12 weeks simultaneously with the hemodialysis sessions. Patients exercised for 20 min during the first $2 \mathrm{~h}$ of the hemodialysis using the electric exercise bike (Model number: TD001P-1-A\#5815, Brand name: TODO, Origin: China) (Additional file 1).

Since patients experience fluid accumulation in the body before hemodialysis begins, such excess fluids must be removed within $4-5 \mathrm{~h}$. This rapid release of fluids from the body can sometimes lead to hemodynamic changes and symptoms such as hypotension or cramps [26]. Therefore, based on the researcher's clinical experience, physician recommendations, and literature review, the best time for intervention is $30 \mathrm{~min}$ after the initiation and during the first $2 \mathrm{~h}$ of dialysis [27]. The researcher placed the bike on the bed, fixed the patient's feet to the pedals using adhesive straps, and knee range of motion was determined for each subject. Patients performed passive pedaling at low power for $20 \mathrm{~min}$ at a speed of $30 \mathrm{rpm}$ during the first $2 \mathrm{~h}$ of every dialysis session. Participants were instructed on how to exercise and verbal encouragement was provided to them during exercise. Before, during, and after exercise, clinical assessment, blood pressure, heart rate and body temperature were obtained. If the participant had a blood pressure of 180/110 $\mathrm{mmHg}$ and higher, systolic pressure lower than $90 \mathrm{mmHg}$, chest pain, shortness of breath, or high body temperature $(>37.8 \mathrm{oC})$ before or during dialysis, the exercise would be discontinued. None of the patients suffered from such complications and all participated without interruption.

The two groups filled the MFI at the end of each month (1-3, and) during the intervention and 1 month after the intervention. Given the assumption that continuous, long-term exercise can affect the level of fatigue, the study attempted to measure the effect of longterm exercise on fatigue ( 3 months) as well as the level of fatigue at different times (1 month, 2 months, 3 months, and 1 month after intervention). The study lasted from 15 October 2018 to 22 April 2019.

\section{Data analysis}

Data were analyzed by SPSS 18 . Descriptive statistics were used to describe the demographic and clinical characteristics of the participants and other variables of the study. The independent t-test, chi-squared test, and
Fisher's test were used to compare the demographic and clinical characteristics of the samples between the two intervention and control groups. Since the parametric conditions were confirmed, the repeated measures ANOVA was used to compare the fatigue scores within each group and between the groups at different times. A $P$-Value below 0.05 was considered significant. There were some instances of missing data in relation to some questions in various measurements of the fatigue scale. As the fatigue scores had normal distribution at all times in both groups, the missing values were replaced with the mean in each group.

\section{Results}

The mean ages were $57.8 \pm 9.17$ yrs. and $54.65 \pm 10.02$ yrs. in the intervention and control groups, respectively. There were no significant differences between the two groups in age, gender, education, the number of children, income, exercise, history of dialysis, history of transplant rejection, cause of disease, and history of other diseases $(P>0.05)$ (Table 1$)$.

The mean total score of fatigue in the experimental group was $58.80 \pm 15.29$ in the beginning, and continuously decreasing in the first month $(58.78 \pm 13.54)$, second month (58.75 \pm 14.73$)$, third month $(54.20 \pm 15.16)$, and 1 month post- intervention (54.23 \pm 13.60$)$. However, there were no significant differences within groups at the various time points $(P=0.12)$. The fatigue score in the control group was $64.53 \pm 16.32$ in the beginning, and it steadily increased in the first month $(64.03 \pm 13.91)$, second month $(64.22 \pm 13.07)$, third month $(69.53 \pm 9.22)$, and 1 month after the intervention $(70.34 \pm 7.69)$. However, there were no significant differences within groups at the various time points $(P=0.06)$. The total fatigue score significantly decreased in the intervention group compared with the control group in the third month $(P=0.001)$, and 1 month after the intervention $(P<0.001)$.

Based on these results, during the intervention fatigue was slightly better, although not statistically significant, and were precluded from the progression of fatigue (Table 2, Fig. 2). Results of this study showed that there was a significant difference between the experimental and control groups in subscales of fatigue such as a decline in motivation $(P=0.02)$ and mental fatigue $(P=$ 0.046). Also, there was a significant difference between the experimental and control groups in all subscales of fatigue during the third month of intervention and 1 month after intervention (Table 3). In addition, the results showed that exercise prevented the development of mental fatigue in the experimental group.

\section{Discussion}

The present study showed that exercise with mini bikes prevented increase in fatigue and its subscales, 
Table 1 Comparison of patients' characteristics between the intervention and control groups

\begin{tabular}{|c|c|c|c|c|c|c|c|}
\hline \multirow{2}{*}{\multicolumn{2}{|c|}{$\begin{array}{l}\text { Group } \\
\text { Variable }\end{array}$}} & \multicolumn{2}{|c|}{ The control group } & \multicolumn{2}{|c|}{ The intervention group } & \multirow{2}{*}{$\begin{array}{l}\text { Statistical } \\
\text { test }\end{array}$} & \multirow{2}{*}{$\begin{array}{l}P \\
\text { value }\end{array}$} \\
\hline & & Mean & SD & Mean & SD & & \\
\hline \multicolumn{2}{|l|}{ Age (yr.) } & 54.65 & 10.02 & 57.80 & 9.17 & $0.99^{\mathrm{a}}$ & 0.32 \\
\hline \multirow{2}{*}{\multicolumn{2}{|c|}{ Duration of dialysis (month) }} & 36.94 & 20.37 & 43.5 & 39.19 & $-0.21^{b}$ & \\
\hline & & $\mathrm{n}$ & $\%$ & $\mathrm{n}$ & $\%$ & & \\
\hline \multirow[t]{2}{*}{ Sex } & Female & 4 & 23.5 & 7 & 35 & $0.58^{c}$ & 0.45 \\
\hline & Male & 13 & 76.5 & 13 & 65 & & \\
\hline \multirow[t]{4}{*}{ Education } & Illiterate & 6 & 35.3 & 2 & 10 & $5.6^{d}$ & 0.24 \\
\hline & Under diploma & 4 & 23.5 & 11 & 55 & & \\
\hline & Diploma & 4 & 23.5 & 3 & 15 & & \\
\hline & Academic & 3 & 17.7 & 4 & 20 & & \\
\hline \multirow[t]{3}{*}{ Doing exercise } & Regularly & 0 & 0 & 3 & 15 & $2.89^{d}$ & 0.32 \\
\hline & Sometimes & 8 & 47.1 & 6 & 30 & & \\
\hline & Never & 9 & 52.9 & 11 & 55 & & \\
\hline \multirow[t]{4}{*}{ Cause of kidney failure } & Diabetes & 10 & 58.8 & 12 & 60 & $2.7^{d}$ & 0.75 \\
\hline & Hypertension & 3 & 17.6 & 4 & 20 & & \\
\hline & Polycystic kidney & 2 & 11.8 & 4 & 20 & & \\
\hline & Others & 2 & 11.8 & 0 & 0 & & \\
\hline \multirow[t]{2}{*}{ History of other disease } & Yes & 4 & 23.5 & 11 & 55 & $3.78^{c}$ & 0.053 \\
\hline & No & 13 & 76.5 & 9 & 45 & & \\
\hline
\end{tabular}

a Independent T Test

${ }^{b}$ Mann Whitney U Test

c Chi-squared Test

${ }^{\mathrm{d}}$ Fisher exact test

especially mental fatigue, in the test group. On the other hand, the control group experienced a progressive increase in their fatigue levels, which amounted to a statistically significant level in later months. This intervention supports the study hypothesis that exercise with mini bikes can affect fatigue among hemodialysis patients. The results of this study are important because, on the one hand, patients are increasingly showing interest in non-pharmaceutical methods, and on the other, specialists refuse to include non-pharmaceutical methods that are not scientifically confirmed in their intervention regimens.

The results of the present study showed that most of the participants in the two groups suffered from fatigue before the intervention. Jablonski reported that 69 to $77 \%$ of hemodialysis patients suffered from fatigue and were in need of non-pharmaceutical interventions. According to the study of Lashkari et al., in Iran, 42, 36, and $19 \%$ of hemodialysis patients suffered from high, medium, and low levels of fatigue, respectively [28].

Table 2 Comparison of the fatigue scores at different times between the intervention and the control groups

\begin{tabular}{|c|c|c|c|c|c|c|c|c|c|}
\hline \multirow{2}{*}{$\begin{array}{l}\text { Group } \\
\text { Fatigue score }\end{array}$} & \multicolumn{2}{|c|}{ The control group } & \multicolumn{2}{|c|}{ The intervention group } & \multirow{2}{*}{$\begin{array}{l}\text { Statistical } \\
\text { test }^{a}\end{array}$} & \multirow{2}{*}{$\begin{array}{l}P \\
\text { value }\end{array}$} & \multirow{2}{*}{$\begin{array}{l}\text { Partial } \\
\text { Eta } \\
\text { Squared }\end{array}$} & \multirow{2}{*}{$\begin{array}{l}\text { Mean } \\
\text { Difference }\end{array}$} & \multirow{2}{*}{$\begin{array}{l}P \\
\text { value }^{b}\end{array}$} \\
\hline & Mean & SD & Mean & SD & & & & & \\
\hline Pre intervention & 62.53 & 16.32 & 58.80 & 15.29 & 5.72 & 0.02 & 0.14 & -3.73 & 0.48 \\
\hline First month & 64.03 & 13.91 & 58.78 & 13.54 & & & & -5.25 & 0.25 \\
\hline Second month & 64.22 & 13.07 & 58.75 & 14.73 & & & & -5.47 & 0.24 \\
\hline Third month & 69.53 & 9.22 & 54.20 & 15.16 & & & & -15.33 & 0.001 \\
\hline One month after the intervention & 70.34 & 7.69 & 54.23 & 13.60 & & & & -16.12 & $<0.001$ \\
\hline Greenhouse-Geisser & 3.12 & & 2.25 & & & & & & \\
\hline$P$ value & 0.06 & & 0.12 & & & & & & \\
\hline
\end{tabular}

\footnotetext{
a Repeated measured ANOVA
}

${ }^{\mathrm{b}}$ Adjustment for multiple comparisons: Bonferroni 


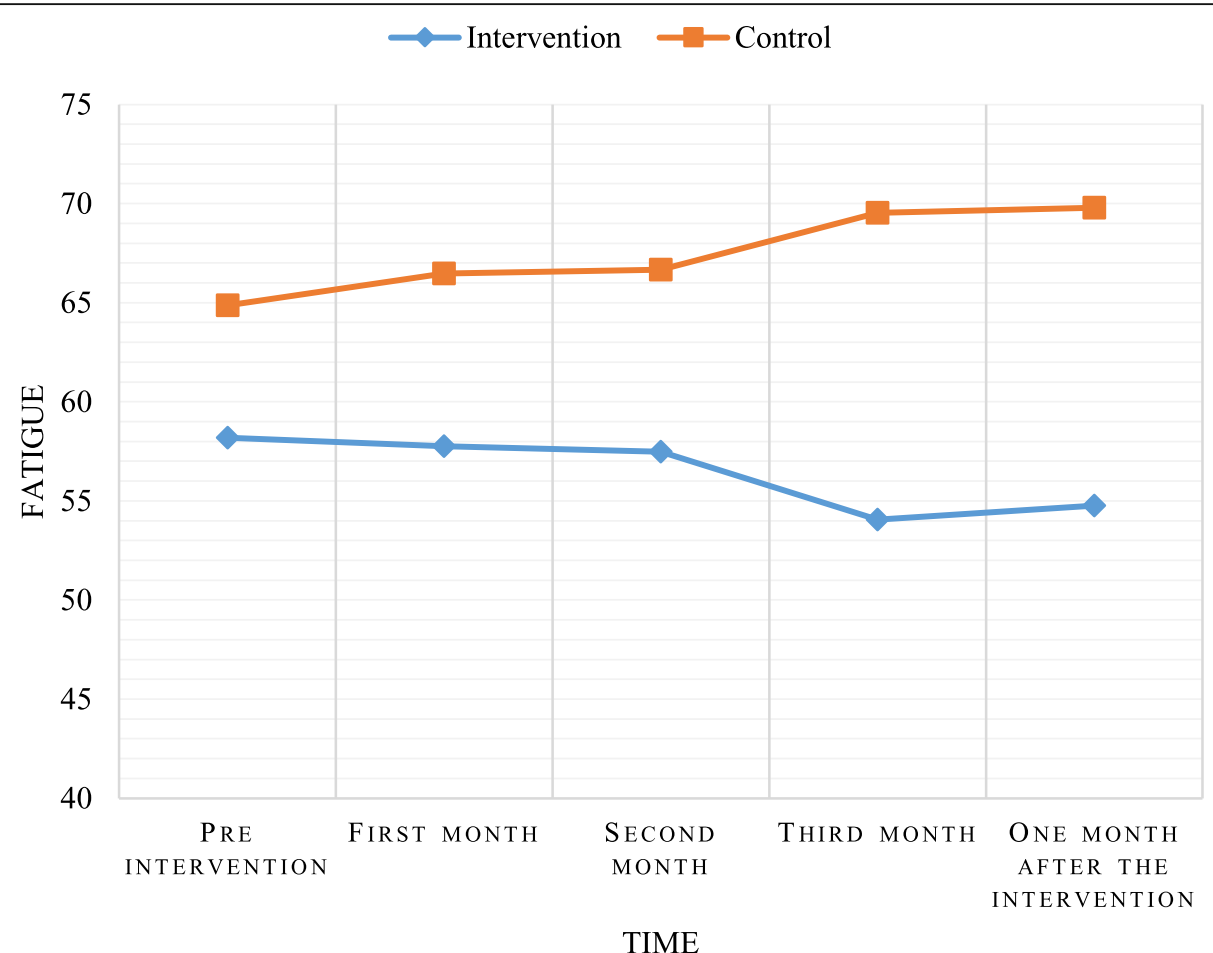

Fig. 2 Comparison of mean fatigue at different times between intervention and control groups

Mohamed et al.reported that the majority of hemodialysis patients in Egypt experienced fatigue [29]. Jhamb et al. noted a $60-97 \%$ prevalence of fatigue in Chinese patients undergoing hemodialysis [30]. Picariello et al., showed that fatigue was common in hemodialysis patients in the UK, and that there was a strong correlation between the mental and physical factors of fatigue [31].

The results of this study showed that there was a significant difference in the levels of fatigue between the experimental and control groups in the second and third months of intervention and 1 month after the intervention. Another notable point was that the level of fatigue increased in the control group over time. It can be deduced from the results of this study that exercise is a particularly promising way to curb the natural progression of fatigue that hemodialysis patients experience through time; the fatigue in patients under hemodialysis will increase if it is not appropriately addressed. In line with our results, Riahi et al. [32], reported a decrease in fatigue and an increase in physical strength among hemodialysis patients after 5 months of exercising on a mini-bike for $60 \mathrm{~min}$ three times a week. According to research by Macdonald et al. [33], exercising three times a week with a suitable bicycle could lead to increased muscle mass in end-stage renal disease (ESRD) patients through adjustment of the insulin-like growth factor. Researchers found that attention to preventing mental fatigue is important because mental fatigue causes symptoms such as lack of motivation, irritability, loss of appetite, and insomnia. Mental fatigue can affect patient quality of life both in the short and in the long term [34]. Similar results were reported by Maniam et al. [20], Soliman et al. [35], Yutkuran et al. [36], Malagoni et al. [37], and Liu et al. [38]. However, these authors employed different kinds of exercise programs such as stretching, intradialytic range of motion exercise programs, yoga-based exercises, walking programs, and aerobic exercises. Maniam et al. [20] showed that $15 \mathrm{~min}$ of stretching before hemodialysis three times a week for 12 weeks could decrease fatigue and improve sleep disorders in patients. According to results of Soliman et al. [35], a significant reduction was seen in the level of fatigue and electrolytes such as serum phosphate, potassium, calcium, urea, and creatinine among ESRD patients undergoing Hemodialysis after an 8-week intradialytic range of motion exercise program. Also, fatigue and musculoskeletal problems were reported to improve with yoga [36]. In addition, an original 6-month walking program was effective on post-dialysis fatigue, physical capacity, and health-related quality of life among hemodialysis patients [37]. The results of Liu et al. [38] suggest that aerobic exercise plays an important role in physical function and decreases depression. Motedayen et al. [39] and Tayyebi et al. [40] showed that body-mind intervention is effective on fatigue and dialysis adequacy. 
Table 3 Comparison of the fatigue dimensions' scores at different times between the intervention and the ontrol groups

\begin{tabular}{|c|c|c|c|c|c|c|c|c|c|c|}
\hline \multirow{2}{*}{\multicolumn{2}{|c|}{$\begin{array}{l}\text { Group } \\
\text { Fatigue dimensions }\end{array}$}} & \multicolumn{2}{|c|}{$\begin{array}{l}\text { The control } \\
\text { group }\end{array}$} & \multicolumn{2}{|c|}{$\begin{array}{l}\text { The intervention } \\
\text { group }\end{array}$} & \multirow[t]{2}{*}{$\begin{array}{l}\text { Statistical } \\
\text { test }^{\mathrm{a}}\end{array}$} & \multirow[t]{2}{*}{$\begin{array}{l}P \\
\text { value }\end{array}$} & \multirow{2}{*}{$\begin{array}{l}\text { Partial } \\
\text { Eta } \\
\text { Squared }\end{array}$} & \multirow[t]{2}{*}{$\begin{array}{l}\text { Mean } \\
\text { Difference }\end{array}$} & \multirow[t]{2}{*}{$\begin{array}{l}P \\
\text { value }^{\mathrm{b}}\end{array}$} \\
\hline & & Mean & SD & Mean & SD & & & & & \\
\hline \multirow[t]{7}{*}{ General Fatigue } & Pre intervention & 12.24 & 3.94 & 12.60 & 3.44 & 1.88 & 0.18 & 0.05 & 0.36 & 0.77 \\
\hline & First month & 12.94 & 3.53 & 12.72 & 3.37 & & & & -0.22 & 0.84 \\
\hline & Second month & 12.88 & 3.5 & 12.61 & 3.20 & & & & -0.26 & 0.80 \\
\hline & Third month & 13.93 & 3.10 & 10.95 & 5.17 & & & & -2.98 & 0.04 \\
\hline & One month after the intervention & 14.19 & 2.74 & 10.83 & 4.38 & & & & -3.36 & 0.007 \\
\hline & Greenhouse-Geisser & 4.36 & & 2.08 & & & & & & \\
\hline & $P$ value & 0.01 & & 0.14 & & & & & & \\
\hline \multirow[t]{7}{*}{ Physical Fatigue } & Pre intervention & 14.53 & 4.16 & 13.75 & 4.69 & 2.81 & 0.10 & 0.07 & -0.78 & 0.60 \\
\hline & First month & 13.69 & 2.87 & 13.39 & 3.68 & & & & -0.30 & 0.78 \\
\hline & Second month & 14.44 & 3.12 & 13.5 & 3.96 & & & & -0.94 & 0.41 \\
\hline & Third month & 15.67 & 2.13 & 12.21 & 3.54 & & & & -3.46 & 0.001 \\
\hline & One month after the intervention & 15.75 & 1.95 & 12.78 & 4.22 & & & & -2.97 & 0.008 \\
\hline & Greenhouse-Geisser & 3.33 & & 2.62 & & & & & & \\
\hline & $P$ value & 0.04 & & 0.07 & & & & & & \\
\hline \multirow[t]{7}{*}{ Decline in activity } & Pre intervention & 14.71 & 4.97 & 12.95 & 5.42 & 3.94 & 0.05 & 0.10 & -1.76 & 0.32 \\
\hline & First month & 14.25 & 3.97 & 11.83 & 4.63 & & & & -2.42 & 0.09 \\
\hline & Second month & 15.06 & 4.19 & 12.50 & 5.38 & & & & -2.56 & 0.10 \\
\hline & Third month & 15.73 & 2.66 & 13.16 & 5.10 & & & & -2.57 & 0.06 \\
\hline & One month after the intervention & 15.94 & 2.69 & 13.00 & 5.06 & & & & -2.94 & 0.03 \\
\hline & Greenhouse-Geisser & 1.45 & & 0.71 & & & & & & \\
\hline & $P$ value & 0.25 & & 0.52 & & & & & & \\
\hline \multirow[t]{7}{*}{ Decline in Motivation } & Pre intervention & 10.71 & 4.00 & 10.30 & 3.58 & 6.11 & 0.02 & 0.15 & -0.41 & 0.75 \\
\hline & First month & 11.62 & 3.03 & 10.28 & 3.56 & & & & -1.35 & 0.21 \\
\hline & Second month & 11.25 & 3.59 & 9.94 & 3.15 & & & & -1.31 & 0.23 \\
\hline & Third month & 12.73 & 3.22 & 9.26 & 3.44 & & & & -3.47 & 0.002 \\
\hline & One month after the intervention & 12.44 & 3.52 & 9.11 & 3.06 & & & & -3.33 & 0.003 \\
\hline & Greenhouse-Geisser & 1.83 & & 0.99 & & & & & & \\
\hline & $P$ value & 0.18 & & 0.38 & & & & & & \\
\hline \multirow[t]{7}{*}{ Mental Fatigue } & Pre intervention & 10.35 & 4.43 & 9.2 & 3.05 & 4.26 & 0.046 & 0.11 & -1.15 & 0.36 \\
\hline & First month & 11.38 & 3.77 & 10.67 & 3.11 & & & & -0.71 & 0.52 \\
\hline & Second month & 10.44 & 4.15 & 10.33 & 3.72 & & & & -0.10 & 0.93 \\
\hline & Third month & 11.47 & 3.2 & 8.63 & 2.75 & & & & -2.84 & 0.004 \\
\hline & One month after the intervention & 12.06 & 3.71 & 8.44 & 2.28 & & & & -3.62 & 0.001 \\
\hline & Greenhouse-Geisser & 1.42 & & 3.30 & & & & & & \\
\hline & $P$ value & 0.25 & & 0.04 & & & & & & \\
\hline
\end{tabular}

a Repeated measured ANOVA

${ }^{\mathrm{b}}$ Adjustment for multiple comparisons: Bonferroni

It is suggested that exercise combined with mental training can have a positive effect on treatment outcomes. Several studies have demonstrated that exercise during dialysis not only decreases fatigue, but also increases self-confidence and self-efficacy [27, 32, 39]. A systematic meta-analysis study showed that exercise training helps hemodialysis patients to reduce the severity of restless leg syndrome, depression, and fatigue [41].

Researchers believe that exercise widens muscular arteries, improves perfusion, and alleviates diseases affecting blood circulation in muscles [42]. Therefore, due to the improvement in perfusion and enhanced 
blood circulation and better toxin elimination and higher muscular strength, and consequently, lower levels of fatigue and impotence, we can expect improvement in the quality of life of patients undergoing hemodialysis. This study provides a more time-efficient option for exercise among hemodialysis patients as the method used did not necessitate extra time, costs, and transportation. Therefore, it seems that mini-bike exercise is safe and effective in the rehabilitation and complementary treatment of patients undergoing hemodialysis. Another point worth noticing is that the benefits of preventing the progression of fatigue remained at least 1 month after the discontinuation of the exercises. It is concluded that long-term exercise can have a significant impact on preventing long-term fatigue. Researchers believe that an intervention is valuable when its effects are sustained over time [43].

This study had some limitations. Firstly, the knowledge, experience, emotional and mental characteristics, and cultural backgrounds of the patients affected their level of motivation and desire. Moreover, although two main centers were selected, and all eligible patients were included, the sample size decreased due to the dropout. It is recommended that this study be conducted with a larger sample size. Another limitation of this study was that we did not make any objective measurements of fatigue. It is suggested that this issue be considered in future research.

\section{Conclusions}

Altogether, the present study showed that exercising was effective in prevention of progression of fatigue in patients under hemodialysis over time, at least up to 1 month after the intervention. Therefore, as paying attention to hemodialysis patients' quality of life is an important goal of dialysis centers, we can recommend the use of this method to prevent the progression of fatigue in them. According to the experiences of researchers during the study and observing the patients' enthusiasm for doing the exercises, it seems that we need to use these kinds of interventions as non-pharmaceutical therapies combined with other treatments for patients under hemodialysis. Of course, we need to realize that doing these kinds of activities requires informing the health care team members such as the physicians, nurses, and other members about the advantages and the correct way of implementing the exercise program. Finally, it is recommended that other studies focusing on comparing the effectiveness of exercise therapy and pharmaceutical therapy on fatigue in hemodialysis patients be conducted to provide better service to the patients. It should also be pointed out that further research is required to determine the optimal exercise prescription guidelines for hemodialysis patients.

\section{Supplementary information}

Supplementary information accompanies this paper at https://doi.org/10. 1186/s13102-020-00165-0.

Additional file 1. Is a photo of the mini bike was used in this study. This photgraph was taken by the authors.

\section{Abbreviations}

ESRD: End-Stage Renal Disease; MFI: Multidimensional Fatigue Inventory

\section{Acknowledgments}

The present article has been derived from the M. S thesis for critical care nursing. We would thank all patients, the nursing staff of the hemodialysis centers, the graduate department of Razi Faculty of Nursing and Midwifery of Kerman that helped us in this research.

\section{Authors' contributions}

PM and FS contributed to original idea and protocol, conception of the work, conducting the study, revising the draft, approving the final version of the manuscript, and agreed for all aspects of the work. MD was involved in data analysis, drafting of the manuscript and approval of the final version of the manuscript. ME contributed to the design of the work, the draft revision and approval of the final version of the manuscript. All authors have read and approved the manuscript.

\section{Funding}

Not applicable.

\section{Availability of data and materials}

The datasets used and/or analyzed during the current study are available from the corresponding author on reasonable request.

\section{Ethics approval and consent to participate}

The ethics committee of Kerman University of Medical Sciences approved the study (Ethics code No. IR.KMU.REC.1397.086). Written consent was obtained from all participants in both intervention and control groups, and they were assured that their personal information would remain confidential. Also, exercise therapy was carried out for the control group after the study.

Consent for publication

Not applicable.

\section{Competing interests}

The authors declare that they have no competing interests.

\section{Author details}

${ }^{1}$ Clinical Research Unit, Shafa Hospital, Kerman University of Medical Sciences, Kerman, Iran. ${ }^{2}$ Nursing Research Center, Kerman University of Medical Sciences, Kerman, Iran. ${ }^{3}$ Nursing Research Center, Razi Faculty of Nursing and Midwifery, Kerman University of Medical Sciences, Kerman, Iran. ${ }^{4}$ Department of Urology, Bahonar Hospital, Kerman University of Medical Sciences, Kerman, Iran

Received: 7 September 2019 Accepted: 21 February 2020

Published online: 18 March 2020

\section{References}

1. Urquhart-Secord R, Craig JC, Hemmelgarn B, Tam-Tham H, Manns B, Howell $M$, et al. Patient and caregiver priorities for outcomes in hemodialysis: an international nominal group technique study. Am J Kidney Dis. 2016;68(3): 444-54.

2. Saglimbene V, Natale P, Palmer S, Scardapane M, Craig JC, Ruospo M, et al. The prevalence and correlates of low sexual functioning in women on hemodialysis: a multinational, cross-sectional study. PLoS One. 2017;12(6):e0179511.

3. Yaghoubinia F, Navidian A, Yousefian N, Chaji F. Effect of care plan based on Roy adaptation model on physiological adaptation in patients with thalassemia major. Med Surg Nursing J. 2017;6(2):38-43.

4. Ann B, Wellard S, Caltabiano M. Levels of fatique in people with ESRD living in far North Queensland. J Clin Nurs. 2008;17(1):90-8. 
5. O'Sullivan D, McCarthy G. An exploration of the relationship between fatigue and physical functioning in patients with end stage renal disease receiving haemodialysis. J Clin Nurs. 2007;16(11c):276-84.

6. Zakeri MM, Shaban M, Kazemnejad A, Tavasoli K. The effect of breathing exercises on fatigue level of COPD patients; 2006.

7. Ju A, Unruh ML, Davison SN, Dapueto J, Dew MA, Fluck R, et al. Patientreported outcome measures for fatigue in patients on hemodialysis: a systematic review. Am J Kidney Dis. 2018;71(3):327-43.

8. Tamadon MR, Toussy J, Soleimani A, Moghimi J, Malek F, Moradi A, et al. An Evaluation of the Effects of Oral Carnitine in Decreasing Complications of Chronic Hemodialysis at Fatemieh Hospital in Semnan. Sci Magazine Yafte. 2008;9(4):27-32.

9. Zafar Mohtashami A, Hadian B, Lashkarara GR, Mahdipanah F. Dialysis adequacy in chronic hemodialysis patients in Shohada Ashayer Hospital, Khorramabad, Lorestan, Iran. Sci Magazine Yafte. 2017:18(4):13-20.

10. Voigt L, Baumann S, Ullrich A, Weymar F, John U, Ulbricht S. The effect of mere measurement from a cardiovascular examination program on physical activity and sedentary time in an adult population. BMC Sports Sci Med Rehabil. 2018;10(1):1

11. Khazaei Z, Rajabfardi Z, Hatami H, Khodakarim S, Khazaei S, Zobdeh Z. Factors associated with end stage renal disease among hemodialysis patients in Tuyserkan City in 2013. Pajouhan Sci J. 2014;13(1):33-41.

12. Crowther F, Sealey R, Crowe M, Edwards A, Halson S. Influence of recovery strategies upon performance and perceptions following fatiguing exercise: a randomized controlled trial. BMC Sports Sci Med Rehabil. 2017;9(1):25.

13. Arian M, Mortazavi $\mathrm{H}$, TabatabaeiChehr M, Ildarabadi E, Varvani Farahani $\mathrm{A}$, Kamali A, et al. Relationship between activity level and perceived barriers and motivations to exercise in hemodialysis patients. J North Khorasan Univ Med Sci. 2014;6(3):483-95.

14. Kopple JD, Kim JC, Shapiro BB, Zhang M, Li Y, Porszasz J, et al. Factors affecting daily physical activity and physical performance in maintenance dialysis patients. J Ren Nutr. 2015;25(2):217-22.

15. Delgado C, Johansen KL. Barriers to exercise participation among dialysis patients. Nephrol Dial Transplant. 2011;27(3):1152-7.

16. Aliasgharpour M, Hadiyan Z. Assessment of a Designed Exercise Program on Physical Capacity using Six-Minute Walking Test (6MWT) in hemodialysis patients. Hayat. 2011;17(3):59-68.

17. Balaban ÖD, Aydin E, Keyvan A, Yazar MS, Tuna Ö, Devrimci ÖH. Psychiatric comorbidity, sexual dysfunction, and quality of life in patients undergoing hemodialysis: a case-control study. Noro psikiyatri arsivi. 2017;54(2):137-42.

18. Tekdöp Demircioðlu D, Kavadar G, Esen Öre Ö, Emre TY, Yaka U. Relationship between restless leg syndrome and quality of life in uremic patients. Aðrrý. 2015;27(2):73-8.

19. Depression C, Group SdiHW. Prevalence and correlates of erectile dysfunction in men on chronic haemodialysis: a multinational crosssectional study. Nephrol Dial Transplant. 2011;27(6):2479-88.

20. Maniam R, Subramanian P, Singh SKS, Lim SK, Chinna K, Rosli R. Preliminary study of an exercise programme for reducing fatigue and improving sleep among long-term haemodialysis patients. Singap Med J. 2014;55(9):476.

21. Smets E, Garssen B, Bd B, De Haes J. The multidimensional fatigue inventory (MFI) psychometric qualities of an instrument to assess fatigue. J Psychosom Res. 1995;39(3):315-25.

22. Saffari $\mathrm{M}$, Naderi $\mathrm{M}$, Piper $\mathrm{C}$, Koenig $\mathrm{H}$. Multidimensional fatigue inventory in people with hepatitis B infection: cross-cultural adaptation and psychometric evaluation of the Persian version. Gastroenterol Nurs. 2017; 40(5):380-92. https://doi.org/10.1097/SGA.0000000000000250.

23. Lundh Hagelin C, Wengström $Y$, Runesdotter S, Johan FC. The psychometric properties of the Swedish multidimensional fatigue inventory MFI-20 in four different populations. Acta Oncol. 2007;46(1):97-104.

24. Lin J-MS, Brimmer DJ, Maloney EM, Nyarko E, BeLue R, Reeves WC. Further validation of the multidimensional fatigue inventory in a US adult population sample. Popul Health Metrics. 2009;7(1):18.

25. Fillion L, Gélinas C, Simard S, Savard J, Gagnon P. Validation evidence for the French Canadian adaptation of the multidimensional fatigue inventory as a measure of cancer-related fatigue. Cancer Nurs. 2003;26(2):143-54.

26. Flythe JE, Kimmel SE, Brunelli SM. Rapid fluid removal during dialysis is associated with cardiovascular morbidity and mortality. Kidney Int. 2011; 79(2):250-7.

27. Dashtidehkordi A, Shahgholian N, Attari F. Exercise during hemodialysis and health promoting behaviors: a clinical trial. BMC Nephrol. 2019;20(1):96. https://doi.org/10.1186/s12882-019-1276-3.
28. Farhad L, Brazparandjani S, Latifi SM, Chahkhoei M, Khalili A, Paymard A, et al. The effect of collaborative care model on the fatigue in patients undergoing maintenance hemodialysis: a randomized clinical trial. Qom Univ Med Sci J. 2016;10(8):71-9.

29. Mohamed SA. The effectiveness of an educational intervention on fatigue in hemodialysis patients: a randomized controlled trial. J Nurs Health Sci. 2014; 3(4):40-50.

30. Yanbo J, Liu H, Chunlu B, Zhang M, Wei S, Gao G, et al. Fatigue in patients receiving maintenance dialysis: a review of influence factors andinterventions. Chin J Pract Nursing. 2017;33(9):717-20.

31. Picariello F, Moss-Morris R, Macdougall I, Chilcot J. Measuring fatigue in haemodialysis patients: psychometric properties of the Chalder fatigue questionnaire (CFQ). Eur Health Psychol. 2016;18(S):969.

32. Riahi Z, Esfarjani F, Marandi M, Bayat A, Kalaly N. The effects of regular exercise program on dialysis efficacy, muscle atrophy and physical performance in hemodialysis patients. J Shahrekord Univ Med Sci. 2012; 14(5):63-73.

33. Macdonald JH, Phanish MK, Marcora SM, Jibani M, Bloodworth LL, Holly JM, et al. Muscle insulin-like growth factor status, body composition, and functional capacity in hemodialysis patients. J Ren Nutr. 2004;14(4):248-52.

34. Kao TW, Lai MS, Tsai TJ, Jan CF, Chie WC, Chen WY. Economic, social, and psychological factors associated with health-related quality of life of chronic hemodialysis patients in northern Taiwan: a multicenter study. Artif Organs. 2009:33(1):61-8.

35. Soliman HMM. Effect of intradialytic exercise on fatigue, electrolytes level and blood pressure in hemodialysis patients: a randomized controlled trial. $J$ Nurs Educ Pract. 2015;5(11):16-28.

36. Yurtkuran M, Alp A, Dilek K. A modified yoga-based exercise program in hemodialysis patients: a randomized controlled study. Complement Ther Med. 2007;15(3):164-71.

37. Malagoni AM, Catizone L, Mandini S, Soffritti S, Manfredini R, Boari B, et al. Acute and long-term effects of an exercise program for dialysis patients prescribed in hospital and performed at home. J Nephrol. 2008;21(6):871-8.

38. Liu Y-M, Chung Y-C, Chang J-S, Yeh M-L. Effects of aerobic exercise during hemodialysis on physical functional performance and depression. Biol Res Nurs. 2015;17(2):214-21.

39. Motedayen Z, Nehrir B, Tayebi A, Ebadi A, Einollahi B. The effect of the physical and mental exercises during hemodialysis on fatigue: a controlled clinical trial. Nephrourol Mon. 2014;6(4):e14686.

40. Tayyebi A, Babahaji M, Sadeghi Sherme M, Ebadi A, Eynollahi B. Study of the effect of hatha yoga exercises on dialysis adequacy. Iran J Crit Care Nurs. 2012:4:183-90.

41. Song YY, Hu RJ, Diao YS, Chen L, Jiang XL. Effects of Exercise Training on Restless Legs Syndrome, Depression, Sleep Quality, and Fatigue Among Hemodialysis Patients: A Systematic Review and Meta-analysis. J Pain Symptom Manage. 2018;55(4):1184-95. https://doi.org/10.1016/j. jpainsymman.2017.12.472.

42. Afshar R, Shegarfy L, Shavandi N, Sanavi S. Effects of aerobic exercise and resistance training on lipid profiles and inflammation status in patients on maintenance hemodialysis. Indian J Nephrol. 2010;20(4):185.

43. Werch CEC, Moore MJ, Bian H, DiClemente CC, Huang I-C, Ames SC, et al. Are effects from a brief multiple behavior intervention for college students sustained over time? Prev Med. 2010;50(1-2):30-4.

\section{Publisher's Note}

Springer Nature remains neutral with regard to jurisdictional claims in published maps and institutional affiliations.

Ready to submit your research? Choose BMC and benefit from:

- fast, convenient online submission

- thorough peer review by experienced researchers in your field

- rapid publication on acceptance

- support for research data, including large and complex data types

- gold Open Access which fosters wider collaboration and increased citations

- maximum visibility for your research: over $100 \mathrm{M}$ website views per year

At $\mathrm{BMC}$, research is always in progress.

Learn more biomedcentral.com/submission 